\title{
Prototype of Gas Leaking Monitoring Device In Gas Distribution Pipe of PT. Prima Gasifikasi Indonesia in Tanjung Batu
}

\author{
Eko Prayetno ${ }^{1, *}$, Deny Nusyirwan ${ }^{2}$, Ryan Ramadhan Putra ${ }^{1}$, Randika Saputra ${ }^{1}$, and Bayu Anggara ${ }^{1}$ \\ ${ }^{1}$ Department of Eelctrical Engineering, Faculty of Engineering, Universitas Maritim Raja Ali Haji, Jalan Politeknik Km. 24 \\ Kelurahan Senggarang, Kecamatan Tanjungpinang Kota, Kota Tanjungpinang 29115, Provins Kelupauan Riau, Indonesia \\ ${ }^{2}$ Department of Naval Engineering, Faculty of Engineering, Universitas Maritim Raja Ali Haji, Jalan Politeknik Km. 24 \\ Kelurahan Senggarang, Kecamatan Tanjungpinang Kota, Kota Tanjungpinang 29115, Provins Kelupauan Riau, Indonesia \\ *Corresponding Author: ekoprayetno@umrah.ac.id
}

\section{Article history}

Received: 06.08.2020

Revised: 13.09 .2020

Accepted: 30.09 .2020

DOI:10.31629/jit.v1i2.3170

\begin{abstract}
This study aims to help PT. Prima Gasifikasi Indonesia makes a device that detects leaks in gas distribution pipes based on microcontroller technology. This gas detector is connected to several virtual devices that make this tool work well, namely the MQ-2 sensor working as a gas detector, NodeMCU to control the device's controls. As a notification sender to Android, the LED indicates the tool is active, and the buzzer is the provider. Information with a voice indicator. This detector can detect gas to a 'distance 'of less "than ' 25 $\mathrm{cm}$ 'from the sensor. The input on this device, namely MQ-2, will be sent directly to NodeMCU using programming, namely $\mathrm{C}$ language when detecting gas. From the device, two conditions will appear, the first condition is LOW when the device does not detect gas and the second condition is HIGH; namely, the device is medium detects gas caused by a leaky pipe, if the device detects gas, the 'systems will command the output in the form of a buzzer as a sound indicator to sound and provide a notification sent via the Internet to Android by giving a message that the gas has been detected.
\end{abstract}

Keywords: gas leaking, voice indicator, virtual devices, microcontroller

\section{Introduction}

PT. Prima Gasifikasi Indonesia, Kundur is a power plant company that uses biomass fuel. Biomass is processed in the form of wood using the Biomass Gasification Engine System (BGES). The gases produced from this processing are $\mathrm{CO}$, hydrogen, and methane ( $\mathrm{CH} 4)$ [1]. This gas is flammable and dangerous; if humans are directly contaminated, it can cause various diseases such as lung disorders, reduced blood element concentration, dizziness, and even heart attack [2].

At PT. Prima Gasifikasi Indonesia, there are many gas pipelines in processing wood into gas, and many people interact directly with these pipes to carry out checking, regulation, and repair. These pipes can leak due to technical faults and the age of the pipes caused by the weather.

Thus the development of technology in the world continues, many activities are positive to do man, his example by making the gas detection equipment. This tool can regulate the field of 
security so as not to leak gas. [3] The gas setting could be used to protect humans from being on fire and caused by a gas leak, and humans are also protected from poisoning or other diseases if the man inhales directly when they are checking gas.

Previously, there was a lot of research on detecting gas, for instance, as a measuring tool in clicking test custody of carbon monoxide gas [4]. This research aims to measure carbon monoxide gas using the MQ-7 sensor to avoid carbon monoxide gas pollution affecting humans and impacting flora and fauna's survival.

Then in the following research regarding the detection or monitoring device for LPG gas leaks [5]. This tool works by detect leaks in LPG gas, and the use of the tool can use the phone connected to the Internet constantly, usually called IoT (Internet of things), so that users can take advantage of the Internet to send data. The goal of making this tool is to avoid fires and explosions from LPG gas cylinders and to be able to monitor continuously with a cellphone at a considerable distance.

Subsequent research is in the form of detecting levels in the air [6]. The goal is to find out the air and pollution levels that can be harmful to human health. For example, such as in motorized vehicle fumes, because smoke from motorized vehicles is a substance that is harmful to humans.

Several problems have been concluded, namely regarding gas leakage, for processing wood into gas as fuel for power plants at PT. Prima Gasification Indonesia. Researchers will design a tool for detecting gas leaks based on a microcontroller using the MQ-2 sensor. Nexus devices at this in square to detect a gas leak in the pipe distributor. The system monitoring and automatic level can use modern systems application with an Android [7-8]. So, then when there is detected no leaks in pipes that lead the gas out, this tool directly sends a notification to the Android to use additional applications in the form of blynk that platform in the form of software OS mobile (Android and ios) aims to control several modules such as raspberry pi, NodeMCU, Arduino, Wemos, and other modules connected to the 'internet' network as a warning and make it easier for users to deal with leaks in gas pipes.

\section{Materials and Methods}

The gas leak detection system design uses several important items, namely, the MQ-2 sensor as input, NodeMCU as data processing, and LEDs. At the same time, buzzer and Android are the output. Figure 1 shows the MQ-2 sensor as a gas detector; if the sensor does not detect gas caused by a leak in the gas supply pipe, NodeMCU will respond continuously until it detects a gas leak.

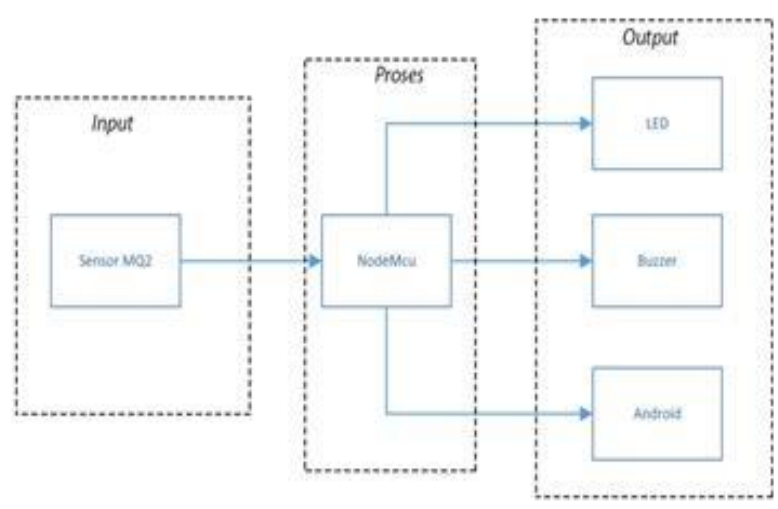

Figure 1. Block diagram of device processes

The MQ-2 sensor serves as input. Input's from sensor MQ-2 are sent to NodeMCU as processors late the data in the form of ADC (Analog To Digital Converter), sending data on the gain from the sensor MQ-2 will apply to use the programming language is the $\mathrm{C}$ language using software Arduino.

Using this programming language, the data is sent to the output in a Buzzer, which provides an indicator in a sound. An android will receive a notification to the Blynk application with the information that gas is detected.

The gas leak detector is made by having a path that has been assembled, as shown in Figure 2, where all the main components will be connected to the NodeMCU. NodeMCU as a command or processor for all components. The sensor on the MQ2 has four pins, namely ground (GND), VCC, analog (A0), digital (D0) [9].

The buzzer and LED have two pins, namely $(+)$ and (-). In the sensor MQ-2 only using 3 Pin connected to NodeMCU, which is connected to A0 A0 pin NodeMCU, VCC connected to $3.3 \mathrm{~V}$, and GND connected to GND on NodeMCU. While on pin $(+)$, the buzzer is connected to pin D1 of NodeMCU, and pin (-) is connected to GND NodeMCU. Then on pin (+), the LED is connected to D2 NodeMCU, and pin (-) is connected to pin GND NodeMCU. 


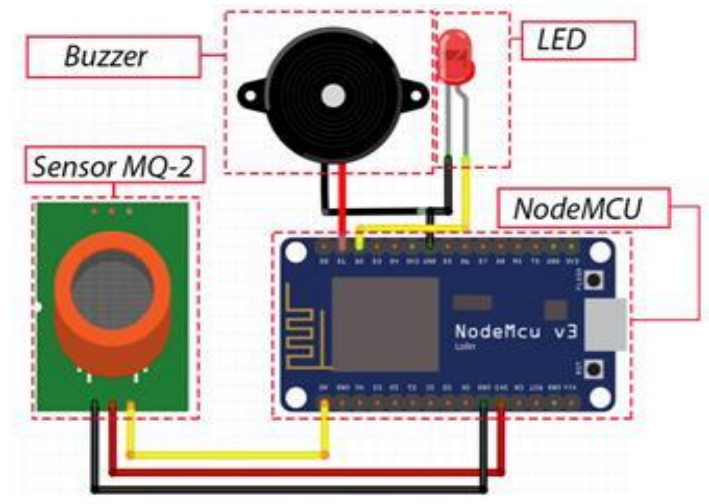

Figure 2. The flow of device sequences

The tool's workings are that the tool will detect leaks in pipelines for gas with used sensor MQ-2 are constantly working on the pipe-conduit to detect the presence of gas. This device is made for monitoring and detecting a microcontroller leak in the gas pipe. The MQ- sensor two can detect some substance that is $\mathrm{H} 2, \mathrm{CH} 4, \mathrm{CO}$, and smoke.

In figure 3 is the flow of how the device works. If the device is turned on, it is automatically connected to the Android that is different to the user, and then the sensor will detect the gas, the LED lights up to prove that the device is active. If the sensor detects a gas pressure that exceeds $350 \mathrm{ADC}$, the data will be sent to NodeMCU. In NodeMCU, the sensor's data will be processed, and NodeMCU orders the buzzer as a sound indicator to sound. Then NodeMCU sends a notification to the blynk in the form of gas that has been detected.

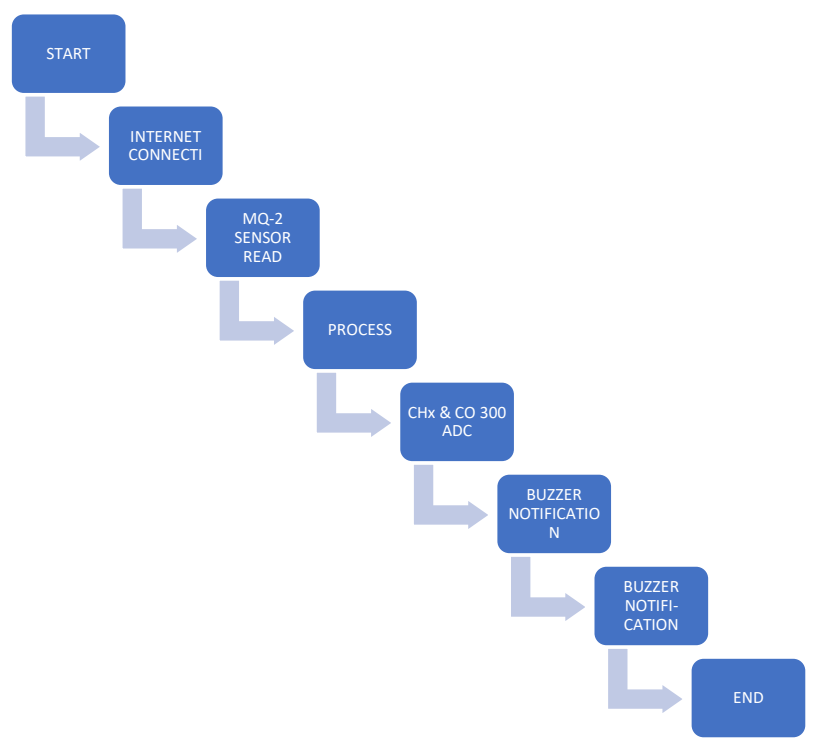

Figure 3. Gas Detector Flow Chart

\section{Testing and Analysis}

This research requires testing for NodeMCU, which must use a multimeter measuring instrument by measuring the PIN used; the aim is to use the PIN in arranging the circuit whether it works well. This research will conduct a direct test on the analog port, namely A0 and the digital port on D1 and D2, to see the condition of each PIN used. The output voltage must also be measured to determine whether the voltage at the output is synchronous or according to the datasheet. Table 1 shows that the NodeMCU test on the pins used are A0, D1, and D2 using a VDC voltage when HIGH is 3.27 Volt, and LOW is 0.5 Volt. It means that NodeMCU is in good condition and following the existing datasheet.

Table 1. Test Results for NodeMCU

\begin{tabular}{ccc}
\hline PIN & $\begin{array}{c}\text { HIGH } \\
\text { (Voltage VDC) }\end{array}$ & $\begin{array}{c}\text { LOW } \\
\text { (Voltage VDC) }\end{array}$ \\
\hline A0 & 3,27 & 0,5 \\
D1 & 3,27 & 0,5 \\
D2 & 3,27 & 0,5 \\
\hline
\end{tabular}

This study uses direct testing to the MQ-2 sensor to see the sensor's speed to detect gas and the distance the sensor can detect. This test aims to see how far the range can be detected and the gas caught on the sensor, which has four states: empty, little, medium, and many. This test using smoke because smoke also contains a substance that the sensor, namely $\mathrm{CO}$, can detect. Table 2 shows the distance detected by the sensor; that is, a distance of less than $25 \mathrm{~cm}$ is the range that the sensor can detect. Whereas at a distance above 25 $\mathrm{cm}$, the sensor starts not detecting. Designing this tool will use a distance of less than $25 \mathrm{~cm}$. The aim is that the sensor can maximize its detection of the gas to be detected.

Table 2. Testing the MQ-2 Sensor Distance

\begin{tabular}{ccc}
\hline No. & Distance $(\mathrm{cm})$ & Detection \\
\hline 1 & 5 & detect \\
2 & 10 & detect \\
3 & 15 & detect \\
4 & 20 & detect \\
5 & 25 & detect \\
6 & 26 & undetected \\
7 & 30 & undetected \\
\hline
\end{tabular}


At $t$ a buzzer three below shows the results of the calibration on the sensor MQ-2, which at the time was no gas (empty) result obtained is 294 ADC (Analog to Digital Converter) and less than $350 \mathrm{ADC}$, and at the time of detecting gas little, moderate and many results obtained on the sensor are more than $350 \mathrm{ADC}$, so in the design of this device, it will be set when the gas is detected more than $350 \mathrm{ADC}$ the tool will send a notification that gas has been detected.

Table 3. MQ-2 Sensor Calibration Results

\begin{tabular}{ccc}
\hline No. & GAS & ADC \\
\hline 1 & No Gas & 294 \\
2 & Little & 356 \\
3 & Moderate & 490 \\
4 & A lot & 841 \\
\hline
\end{tabular}

The sensor calibration has been programmed using $\mathrm{C}$ language on NodeMCU if the current 350 ADC device may instruct the buzzer to sound and NodeMCU sends notifications to the Blynk. Due to the MQ-2 sensor, there is a range limit in detecting gas of 5000-20000ppm. Whereas in the test without gas, it does not mean that there are no substances in the air that the MQ-2 sensor can detect, but there are many substances in the air, one of which can be detected by the sensor is methane gas ( $\mathrm{CH} 4$ ) in the air. So the sensor will automatically rise above 250 and less than 350 ADC [10].

The working system of this gas detector is that when the adapter is turned on, the device will actively detect gas that is within the range of the sensor

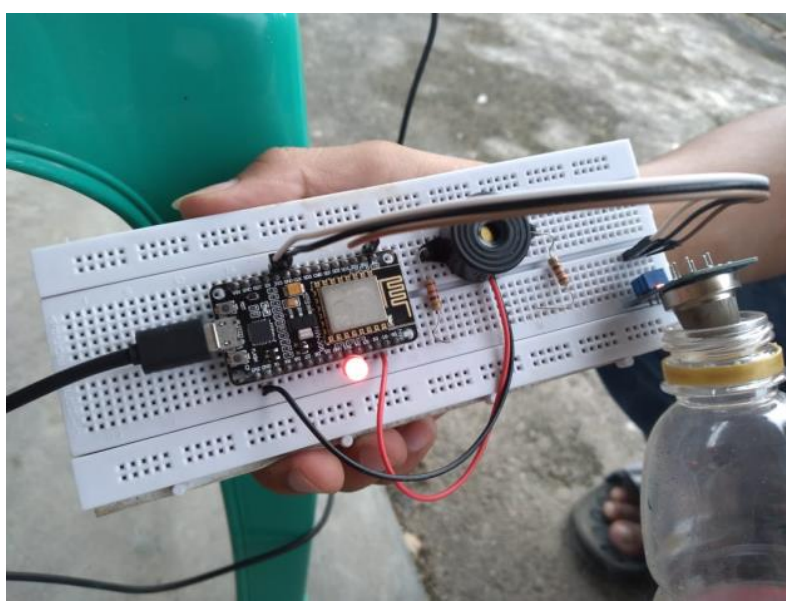

Figure 4. Gas Detector Testing
Advance d nature does the testing for detect gas should see how much power is used gas detection using the goal to help and knowing Performance on gas detection equipment. According to the test results, the device can detect gas around the sensor range with empty, little, medium, and significant conditions, but its detection range is not so wide, ranging from less than $25 \mathrm{~cm}$.

This Blynk is software that Android and IOS can use to manage and view data in the form of ADC that has been set on NodeMCU, Arduino, and similar electronic devices using the internet network as operation.

Testing the blynk application on the device is used to see whether the sensor responds or not. Blynk must also be connected to an internet network connected to Android. Blynk has been set up via NodeMCU to connect to Android using a programming language. Intended use Blynk so the user can fast response $\mathrm{s}$ and facilitate the monitoring remotely.

In figure 5 shows the Blynk application at the time it detects and does not detect. The blynk application will get data sent from NodeMCU continuously as long as the hotspot on the user's Android is connected to the NodeMCU of the device set using programming. The picture explains that the display on Blynk when it is below 300 ADC will not provide notification, while when it reaches more than $350 \mathrm{ADC}$, it will give a message in the form of gas detected. The purpose of using Blynk is to make it easier for users to monitor work remotely and know when a gas leak occurs directly.
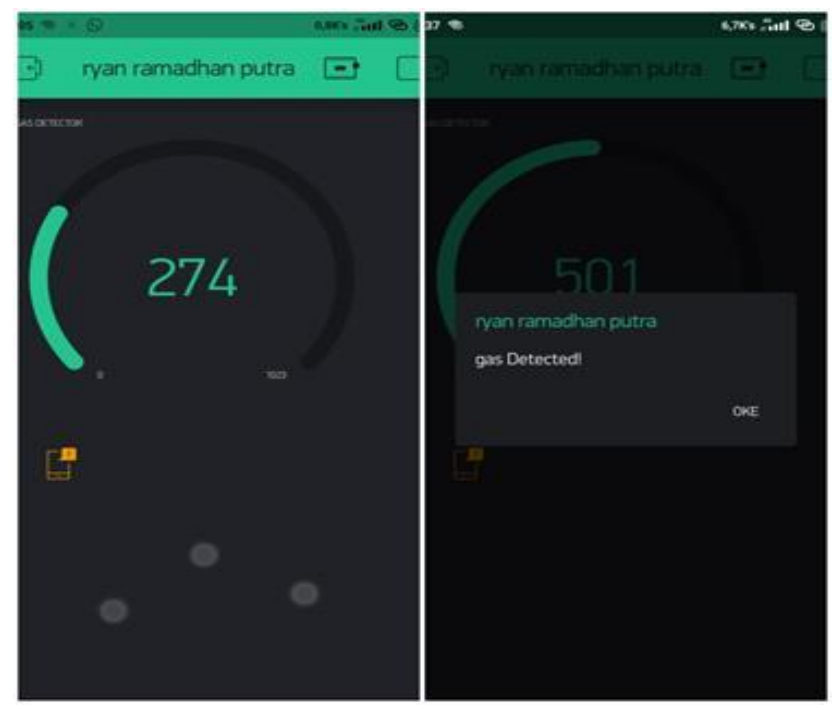

Figure 5. Testing on the Blynk application 
This study uses a testing tool to respond to several devices such as the MQ-2, buzzer, and blynk in an irregular ADC condition with decreased gas emitted. To do this, whether the device can respond or not to the gas. However, the LED is not tested on the device because the LED will light up if the tool is on.

Seen from Table 4 show that the results of the Performance have been set on the appliance with the response sensor that is worth less than 350 ADC stated that all responses from the buzzer and notification on blynk OFF and is not sent, which means that the situation was normal and no detectable gas. Being the excellent value is above 350 ADC, the response on the buzzer and the notification on blynk is $\mathrm{ON}$ and sent, which means the device is detecting the presence of a gas leak. So for this gas detector works well [11].

Table 4. Tool Performance Results

\begin{tabular}{|c|c|c|c|c|}
\hline $\begin{array}{c}\text { Sensor } \\
\text { Response } \\
\text { (ADC) }\end{array}$ & PPM & $\begin{array}{c}\text { Buzzer O } \\
\text { N / OFF }\end{array}$ & $\begin{array}{c}\text { Blynk } \\
\text { SEND / } \\
\text { NO }\end{array}$ & NOTE \\
\hline 268 & 3909 & OFF & NO & NORMAL \\
\hline 280 & 4101 & OFF & NO & NORMAL \\
\hline 292 & 4277 & OFF & NO & NORMAL \\
\hline 303 & 4438 & OFF & NO & NORMAL \\
\hline 527 & 7719 & OFF & NO & NORMAL \\
\hline 354 & 5181 & ON & SEND & DETECTION \\
\hline 377 & 5522 & ON & SEND & DETECTION \\
\hline 405 & 5932 & ON & SEND & DETECTION \\
\hline 493 & 7221 & ON & SEND & DETECTION \\
\hline 838 & 12275 & ON & SEND & DETECTION \\
\hline
\end{tabular}

\section{Conclusion}

PT. Prima Gasification Indonesia is a company that stands in power generation using wood or biomass as fuel. Wood will be processed into gas which produces several kinds of gases, namely CO, hydrogen, and methane ( $\mathrm{CH} 4)$. The gas produced is a gas that is dangerous if it is directly contaminated by humans, which causes poisoning. Therefore this research makes a device that can detect gas caused by a leaky gas pipe. This device requires several main tools, namely the MQ-2 sensor as an input that detects gas, the LED indicates the device is active, NodeMCU as data processing, and once easy to connect to Blynk. Then the buzzer as a warning output is a sound. For MQ-2 sensor can detect several kinds of substances, namely $\mathrm{H} 2, \mathrm{CH} 4, \mathrm{CO}$, and smoke. In the sensor settings, it has been set when detecting gas above 350 ADC it will give a signal. Due to the sensor, there is a range limit that can be detected, namely 5000-10000ppm. In this test, there are also substances in the air that gas can detect, for example, methane (CH4). The sensor will automatically rise to less than $350 \mathrm{ADC}$ even if there is no gas. But if the sensor has a value of more than $350 \mathrm{ADC}$, then there is a gas leak.

\section{References}

[1] Bioenergy., November 2013. PT. Prima Gasifikasi Indonesia, New Hope for National Lightning. pp.19-21

[2] Devita Nur Aprilia, Nurjazuli, Tri Joko Atik. 2017, Environmental Health Risk Analysis of Carbon Monoxide (CO) Exposure to Toll Collector Officers in Semarang. 367-369.

[3] Dedy Hamdani, Elda Handayani \& Eko Risdianto. 2019, Design of Cigarette Smoke and Flame Detection Devices for Health and Fire Management based on Arduino Uno and Gsm Sim900a. 38-45.

[4] Semuel Kete Sarungallo, I Gusti Putu Raka Agung, Lie Jasa. April 2015, Design of Microcontroller-Based Carbon Monoxide (CO) Emission Test Measurement Tool. 141145.

[5] Mifza Ferdian Putra, Awang Harsa Kridalaksana, Zainal Arifin. 2017, Design of L PG Gas Leak Detector Tool With Mq-6 Sensor Based on Microcontroller Using Android Smartphone as Information Media. pp.1-5.

[6] Novianti, Unang Sunarya. 2015, Design Robot Detection Fuzzy Logic-Based Hazardous Environments D an Android Control. 31-32.

[7] Aulia Faqih Rifa'i. May 2016, Gas Leak Detection and Monitoring System (Liquefied Petroleum Gas) Based on Internet Of Things. pp. 5-9.

[8] Maulana Hasan, Adnan Rafi Al Tahtawi. April 2019, Android Integrated Multisensor Fire Early Detector Using Bluetooth Communication. 
[9] Desi Nurnaningsih. October 2018, Lpg Tube Leak Detection Through MSS Gateway Using M Q -2 Sensor Based on Arduino Uno.

[10] Lavanna Indanus Ramadhan, Dahnial Syauqy, Barlian Henryranu Prasetio. November 2017, LPG Gas Leak Detection System Using Fuzzy Method Implemented with Real-Time Operating System (RTOS).
[11] G. N. Eviyanti, E. Prayetno, and E. Prayetno, "Automatic Control Systems for Fish Box Cooler," IJEEPSE, vol. 2, no. 1, pp. 1-5, Feb. 2019. 